\title{
RIKEN wins reviewers' praise
}

Tokyo. The work of Japan's Institute of Physical and Chemical Research (RIKEN) near Tokyo, the country's leading basic research organization, has received high marks from a team of scientists from Japan, Europe and the United States who have carried out an external review of the institute.

In a report to be released today (9 September), the reviewers praise the general level of research being carried out at RIKEN, the standard of its facilities, and the procedures that have been introduced to check that research quality is being maintained.

However, as with a similar review of the physics department of Tokyo University carried out by foreign examiners in January, the reviewers say that the institute should open up its employment practices to attract more of the world's most talented scientists (see Nature, 362, 387; 1993).

In contrast to Europe and the United States, where visiting committees are widely used to assess the quality of research in universities and other institutes, such committees are a new phenomenon in Japan. But they are rapidly gaining popularity as the scientific community seeks to increase its output of basic research.

RIKEN's team of 15 external reviewers, which visited the institute in June, was headed by Heinz Staab, director of the Max-Planck Institute for Medical Research and included George Clark of Massachusetts Institute of Technology, and Nobel prizewinner Heinrich Rohrer of IBM Zurich.

In a report on their three-day visit, the reviewers describe RIKEN's research and facilities as "excellent". Particular praise is directed at the institute's Frontier Research Programme, which employs many foreign scientists - including several project leaders - and which is described as "fostering innovative research of exceptionally high quality and importance".

The reviewers also applaud RIKEN for the way it assesses and monitors the quality of research performed by its scientists. Since 1983, RIKEN has carried out regular external reviews of its chief scientists and their laboratories, an unusual practice in Japan where research leaders tend to protect their projects jealously from outside monitoring.

The reviewers point out, however, that there are almost no foreign scientists on the permanent staff of RIKEN. Those engaged in the Frontier Research Programme are employed on contracts, and there is only one

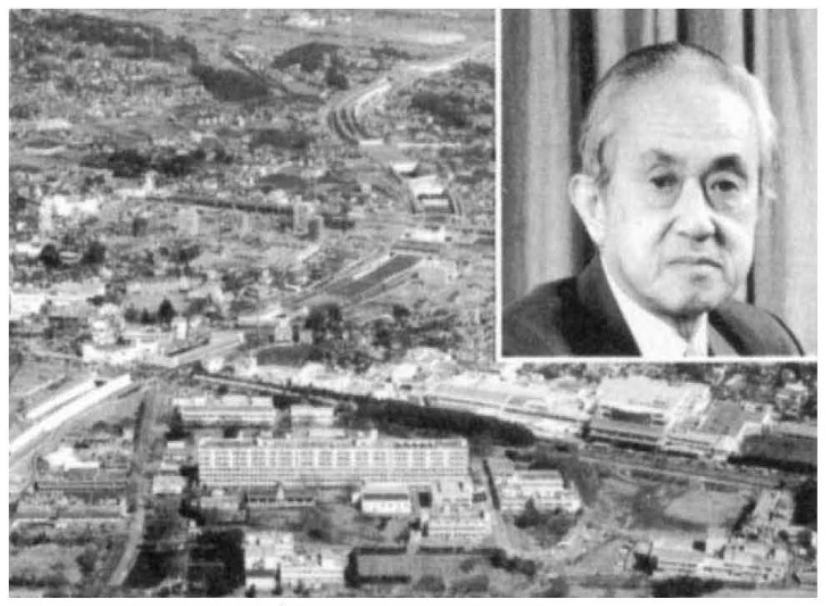

RIKEN's president Oda (Inset) and labs foreign senior scientist among the institute's 313 permanent research staff.

The review team calls for all jobs to be widely advertised. It also suggests extensive use of external referees, including non-Japanese, to assess the international reputation of senior scientists applying for appointments at the institute.

Criticism is also directed at RIKEN's policy of placing an upper age limit of 32 on those appointed to permanent positions below chief scientist. The institute justifies this policy as being necessary to maintain the youth of its research staff. But the reviewers feel that the age limit is too low, as it excludes many talented postdoctoral scientists, and that it should be raised.

In addition to the main report being made public this week, the review team has also delivered draft reports prepared by five subcommittees on research in individual laboratories to Minoru Oda, the president of the institute. These reports will be kept confidential; according to Oda, some of the laboratories are considered to be "surprisingly good", but others are described as being "out of date".

But Oda, who is due to retire shortly, is happy with this conclusion. He believes that, if at least one third of an institute is doing good research, "the rest will follow"; and he says he is pleased that the review shows that this criterion is easily being met at RIKEN.

The institute's board of executive directors is to set up a committee later this month to respond to the review team's recommendations. Unlike Tokyo University, which has made no decision on the future of the review process RIKEN is to repeat the exercise every two years.

David Swinbanks

\section{Japan to boost technology research}

Tokyo. Japan's Ministry of International Trade and Industry (MITI) has asked the government to increase its funding for the Intelligent Manufacturing System (IMS) project - an international programme launched in 1990 and aimed at developing the automated factories of the future - by 48 per cent next year, to a total of $¥ 1.6$ billion (\$150 million).

An even bigger increase is being requested in the amount of money MITI would like to spend on the Real World Computing project, a follow-up to the fifth generation computer project. The ministry wants this to grow by 59 per cent to $¥ 5.7$ billion; and it also hopes to provide a further $¥ 1.4$ billion for the final year of the fifth-generation project.

Meanwhile, the Science and Technology Agency (STA) is hoping to raise the budget for its Exploratory Research for Advanced Technology (ERATO) programme by 8.7 per cent, to permit the launch of four new projects. STA also wants to increase Japan's contribution to the International Thermonuclear Experimental Reactor (ITER) by 22.5 per cent, to $¥ 8.1$ billion.

Both MITI and STA have submitted ambitious budget requests for research and development next fiscal year, which starts on I April, and have managed to avoid the worst of the squeeze on public spending being imposed by the Ministry of Finance (see Nature 365, 7; 1993).

The requests will be trimmed back by the Ministry of Finance before approval by the cabinet at the end of this year. But, on the basis of previous experience, any changes are likely to be relatively small.

MITI’s budget request, for $¥ 301$ billion, is 7.5 per cent higher than this year. One prominent feature is a request for a 16.5 per cent increase in funding for computer networks between MITI’s institutes, to $¥ 2.1$ billion. This coincides with STA's bid for $¥ 1.1$ billion to establish a highcapacity "backbone" computer network linking national research institutes and universities.

STA's request is 6.1 per cent up on this year at $¥ 617$ billion. This includes an 8.9 per cent rise, to $¥ 158$ billion, in the agency’s space budget. Part of this money will be used to cover the rising costs of Japan's contribution to the US Space Station.

No increase is being requested in Japan's contribution to the Human Frontier Science Programme, based in Strasbourg, France. This is provided jointly by MITI and the STA, and the total requested is $¥ 4.2$ billion, the same as last year. But the recent rapid appreciation of the yen means that, when calculated in dollars, the budget for the international programme may well rise above this year.

David Swinbanks 